\title{
Grid-Tied and Stand-Alone Operation of Distributed Generation Modules Aggregated by Cascaded Boost Converters
}

\author{
Reza Noroozian ${ }^{\dagger}$, Gevorg Gharehpetian*, Mehrdad Abedi*, and Mishel Mahmoodi* \\ ${ }^{\dagger}$ Dept. of Electrical Engineering, University of Zanjan, Zanjan, Iran \\ * Dept. of Electrical Engineering, Amirkabir University of Technology, Tehran, Iran
}

\begin{abstract}
This paper presents the modeling, control and simulation of an interconnection system (ICS) of cascaded distributed generation (DG) modules for both grid-tied and stand-alone operations. The overall configuration of the interconnection system is given. The interconnection system consists of a cascaded DC/DC boost converters and a DC/AC inverter. Detailed modeling of the interconnection system incorporating a cascaded architecture has not been considered in previous research. In this paper, suitable control systems for the cascaded architecture of power electronic converters in an interconnection system have been studied and modeled in detail. A novel control system for DC/DC boost converters is presented based on a droop voltage controller. Also, a novel control strategy for DC/AC inverters based on the average large signal model to control the aggregated DG modules under both grid-tied and stand-alone modes is demonstrated. Simulation results indicate the effectiveness of the proposed control systems.
\end{abstract}

Key Words: Distributed Generation (DG), Droop Control, Hysteresis Current Control (HCC), Interconnection System, Modeling, Operation

\section{INTRODUCTION}

Distributed generation (DG) resources are proliferating in electrical utility systems due to economic issues and environmental concerns. Distributed power generation technologies (e.g., fuel cells and microturbines) and renewable technologies (e.g., photovoltaic cells and wind turbines) can be operated in grid-tied and stand-alone modes. Most DG units generate DC power or incompatible AC power. As a result, power electronic interfaces for suitable operation of DG units are very important. The collection of all equipment and functions, taken as a group, used to interconnect a DG unit to the AC grid is called an interconnection system (ICS) [1], [2]. The ICS integrates power electronic conversion systems to interface with a standard AC utility grid. The reference active power of a DG unit is specified by its power management system which should consider various technical and economical constraints. In generators supplied by non-renewable sources, e.g., microturbines and fuel cells, the active power management strategies consider various criteria, such as maximum efficiency conditions or thermal load requirements [3]. In synchronous generators connected to microturbines, power factor control is usually adopted to maximize active power generation [4], [5].

\footnotetext{
Manuscript received Jun. 22, 2008; revised Dec. 5, 2009

† Corresponding Author: noroozian@znu.ac.ir

Tel: +98-241-2283204, Fax: +98-241-2283204, Zanjan University

* Dept. of Electrical Eng., Amirkabir University of Technology, Iran
}

DG units are usually combined with energy storage systems to improve the dynamic performance of the distribution network. The combination of a DG and an energy storage unit forms a hybrid system which is usually called a microsource [6]. Microsources can provide a robust response to changes in the energy manager command.

The desired amount of inertial storage is stored in a DC or AC link implemented in the ICS of DG systems. In the AC link of an ICS, a high frequency AC (HFAC) has been selected due to its benefits; easier filtering of higher order harmonics as well as smaller size and lower cost of passive components. However, HFAC systems have special expensive transformers, complex control structures for AC/AC matrix converters and interaction problems with high frequency converters. As a result, a DC link ICS is preferable to a HFAC link ICS [2].

This paper presents the modeling and control of an ICS of cascaded DG modules with active and reactive power control capability in both grid-tied and stand-alone modes. The DG modules are interfaced with the utility grid via cascaded boost converters and three-phase voltage source converters (VSC). The control strategy for the DC/AC inverter should be able to deliver a preset amount of active and reactive power to the grid or be able to supply an isolated unbalanced AC load with a constant balanced AC voltage magnitude and frequency. However, this paper proposes the current control of a DC/AC inverter for the grid-tied mode and the voltage 


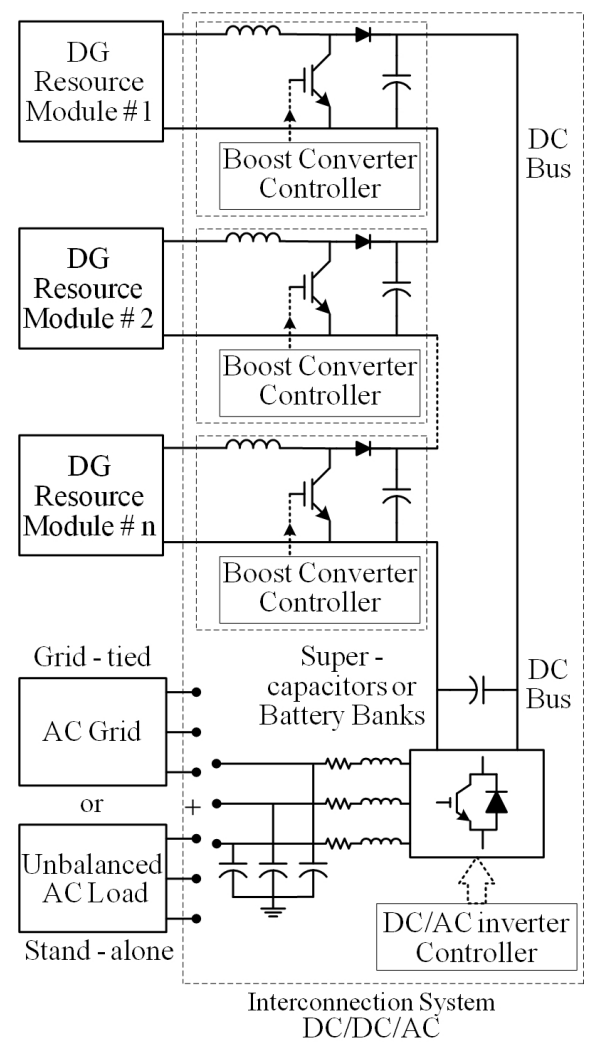

Fig. 1. Interconnection system of cascaded DG modules.

control of a DC/AC inverter for the stand-alone mode. Also, a mathematical model of the DC/AC inverter is derived by using the average large signal model. The proposed system has been modeled and simulated. A simulation based on PSCAD/EMTDC software shows that the generated power from the aggregated DG modules can be controlled. The results also show that the DG resource modules are capable of supplying the unbalanced AC loads with a constant balanced $\mathrm{AC}$ voltage magnitude and frequency.

\section{ICS OF AGGREGATED DG MODULE SYSTEMS}

Fig. 1 shows a schematic diagram of the ICS for multiple DG modules which has been studied in this paper. The basic components of this system are a DG power plant, a DC/DC boost converter and a DC/AC inverter. In recent decades, a voltage source inverter (VSI) capable of both grid-tied and stand-alone operations has been suggested [7]-[10]. Available low power DG units can be connected electrically to yield the necessary power for high power applications. One approach is to connect each DG system separately to the AC utility grid using independent power electronic interfaces. However, using a single DC/AC inverter for all of the DG modules brings the advantages of reduced cost, reduced losses as well as easier design and control of the ICS [7]-[10]. Thus, DG module systems should be aggregated to provide DC input voltage for the DC/AC inverter. In other words, DG modules are connected separately to the DC link using independent DG module converters. The output terminals of the DG module converters at the DC link side can be connected in parallel or in series to control the DC input voltage of the DC/AC inverter.

In this paper, the DC bus voltage is chosen as $V_{d c}=750 \mathrm{~V}$. The controllers of the boost DC/DC converters are designed to keep the DC bus voltage within a specified limit $( \pm 5 \%)$. The DC/AC inverter is a three-phase six-switch VSI with neutral clamped DC capacitors, which interfaces the DC bus with a $220 \mathrm{~V} / 400 \mathrm{~V}$ AC power system. An LC filter connected to the inverter filters the switching frequency harmonics and generates a high quality sinusoidal AC waveform suitable for the load. In this paper, a suitable control strategy for power converters in a cascaded architecture is modeled and presented in detail. The most commonly used DC voltage control method for regulators is the droop controller. A droop controller provides the reference current for the hysteresis current control (HCC) system. This control method has the following advantages over other methods [2]:

- It does not need any fast communication systems.

- Its design procedure is simpler and straightforward.

- It can fulfill the stability requirements more easily.

The DC/AC inverter controller in the on-grid mode controls the active and reactive power delivered from the multiple DG modules to the utility grid. The active and reactive power flows follow specified reference values, which can be set by using power management units. In this method, a current-regulated inverter is implemented for the grid-tied operation because of its ability to deliver sinusoidal current with specified power references to the grid. The DC/AC inverter controller in the off-grid operating mode regulates the unbalanced load voltage of balanced and sinusoidal with constant amplitude and frequency. In this method, the voltage-regulated controllers with outer amplitude and inner waveform control loops based on he $d-q-0$ synchronously rotating reference frame cooperate to drive the aggregated DG modules to supply unbalanced AC loads. In this paper the novel control system for ICS converters (DC/DC boost converters and DC/AC inverter) are presented under different operating conditions.

\section{CONTROL SYSTEM OF BOOST CONVERTERS}

The proposed control strategy for each boost converter is shown in Fig. 2. The DC voltage droop controller specifies the reference current $i_{f d g}^{r e f}$ for the HCC system. The HCC scheme regulates the boost converter inductor current, $i_{f d g}$, within the hysteresis band.

The main part of this strategy is the DC voltage regulator based droop controller. It is obvious that the DC voltage error can be fed to a droop controller whose droop is $R_{d g}$, in order to obtain the injected current (i.e., $i_{d g}$ ) to the DC bus. The multiplication of $v_{d c}$ and $i_{d g}$ determines the injected power to the DC bus of each boost converter (i.e., $P_{d g}$ ). For the DC voltage regulator shown in Fig. 2, we have:

$$
\begin{aligned}
i_{d g} & =\frac{\left(V_{d c}^{r e f}-v_{d c, l p}\right)}{R_{d g}} \\
P_{d g} & =v_{d c} i_{d g}
\end{aligned}
$$

Using equations (1) and (2), we obtain: 
Boost converter

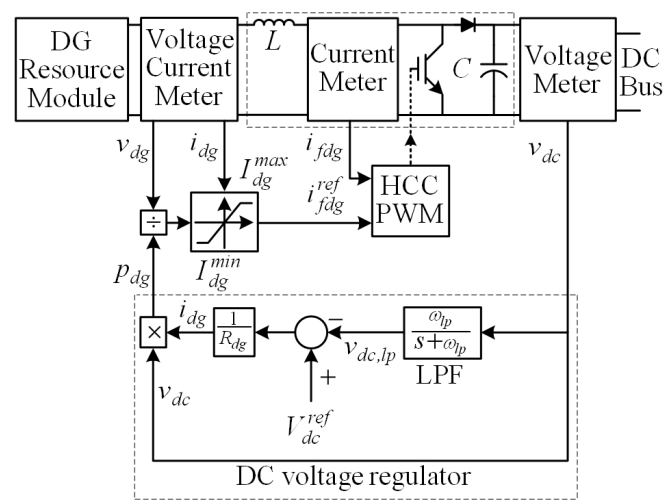

Fig. 2. Proposed control system for each boost converter.

$$
P_{d g}=\frac{v_{d c}\left(V_{d c}^{r e f}-v_{d c, l p}\right)}{R_{d g}}
$$

The reference current, $i_{f b}^{r e f}$, can be obtained as:

$$
i_{f d g}^{r e f}=\frac{P_{d g}}{v_{d g}}
$$

where, $v_{d g}$ is the DG module terminal voltage. This current is limited by upper and lower limits $\left(I_{d g, \max }\right.$ and $\left.I_{d g, \min }\right)$ for the management of the maximum and minimum energy output from the DG resource module. In Fig. 2, the reference current, $i_{r e f}^{f d g}$ and the measured filter current, $i_{f d g}$ are fed to the PWM current control box which determines the switching pattern for each of the boost converters. The above mentioned equations in the steady state condition can be written as follows:

$$
\begin{aligned}
I_{d g} & =\frac{\left(V_{d g}^{r e f}-V_{d c}\right)}{R_{d g}} \\
P_{d g} & =I_{d g} V_{d c} \\
P_{d g} & =\frac{V_{d c}\left(V_{d c}^{r e f}-V_{d c}\right)}{R_{d g}}
\end{aligned}
$$

where $V_{d c}, I_{d g}, V_{d g}^{r e f}$ and $P_{d g}$ are steady the state terminal voltage, the steady state terminal current, the setpoint for the terminal voltage and the steady state active power of the each boost converter, respectively. Equation (7) can be used to verify the simulation results for the steady state active power for each of the DG units. As can be seen from (7), the control system parameters of the boost converters should be identical to obtain equal loading, i.e. proper load sharing of the DG units. The droop, $\delta$, is defined for each boost converter as follows:

$$
\delta=\frac{V_{d c}^{r e f}-V_{d c}}{V_{d c}^{r e f}} \times 100 \%
$$

Equation (7) can be rewritten in the following form:

$$
P_{d g}=\frac{\delta(1-\delta) V_{d c}^{r e f^{2}}}{R_{d g}}
$$

At the rated power conditions, equation (9) can be rewritten as follows:

$$
\begin{gathered}
P_{d g, \text { rated }}=\frac{\delta(1-\delta) V_{d c}^{r e f^{2}}}{R_{d g}} \\
R_{d g}=\frac{\delta(1-\delta) V_{d c}^{\text {ref }}{ }^{2}}{P_{d g, \text { rated }}}
\end{gathered}
$$

A droop coefficient is selected to obtain an acceptable droop under the rated power operation. The capacitor of each boost converter is designed to give the droop controller the performance of a Butterworth filter. Thus, the capacitor for each boost converter is obtained by the following equation [2], [11]:

$$
C=\frac{2}{R_{d g} \cdot \omega_{l p}}
$$

Here, $\omega_{l p}$ is the break-over frequency of the low pass filter (LPF) (shown in Fig. 2) used to measure the DC terminal voltage for each of the boost converters.

$$
\begin{aligned}
C & =\frac{2}{R_{d g} \cdot \omega_{l p}} \\
C & =\frac{2 P_{d g, \text { rated }}}{\delta(1-\delta) V_{d c}^{r e f^{2}} \cdot \omega_{l p}}
\end{aligned}
$$

The inductor of each boost converter is designed to make its current track the reference current within the hysteresis band. Thus, the inductor $L$ for each boost converter is obtained by the following equation [2], [11]:

$$
L=\frac{4 V_{d c}^{r e f}}{h \cdot f_{s, \text { max }}}
$$

where, $h$ is the hysteresis band and $f_{s, \max }$ is the maximum switching frequency of the boost converter.

\section{CONTROL SYSTEMS OF DC/AC INVERTERS}

Grid-tied (or on-grid) mode allows the DC/AC inverter to operate parallel to the grid, providing grid support. Standalone (or off-grid) mode allows the DC/AC inverter to operate completely isolated from the AC grid for supplying unbalanced AC loads by balanced voltages. There can be a dual mode of operation. In this mode, the DC/AC inverter can be automatically switched between the two modes.

\section{A. Control strategy for grid-tied operation}

The average large signal model of a DC/AC inverter in the grid-tied operating condition is shown in Fig. 3. This converter is represented with three ideal current sources $i_{f a}^{r e f}, i_{f b}^{r e f}$ and $i_{f c}^{r e f}$. The converter manages the amount of current injected to the AC grid from the DC bus. As can be seen in Fig. 3, the input signals of the DC/AC inverter are the source phase voltages, $v_{s a}, v_{s b}$ and $v_{s c}$, the three phase output currents for this converter $i_{f a}, i_{f b}$ and $i_{f c}$, the reference of the active power $P_{r e f}$, and the reference of the reactive power $Q_{r e f} \cdot L_{f}$ 


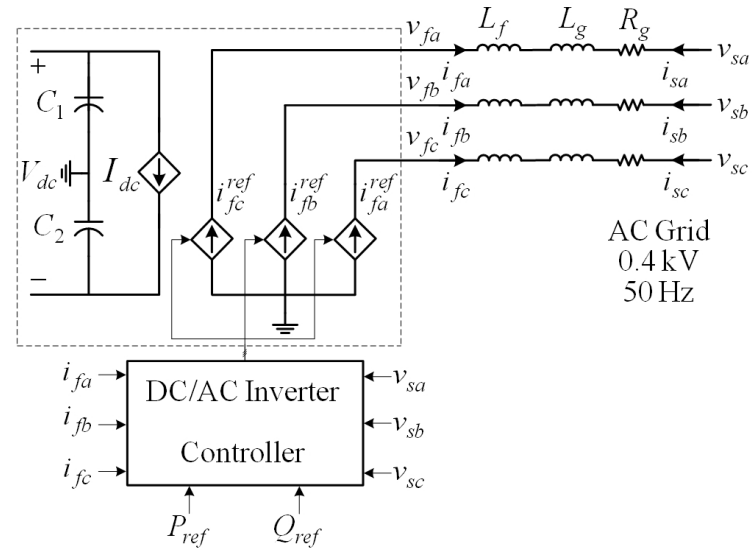

Fig. 3. Average large signal model of the DC/AC inverter in grid-tied mode.

is the inductance of the converter filter. $R_{g}$ and $L_{g}$ are the resistance and inductance of the $\mathrm{AC}$ grid. This controller uses the HCC switching technique. As can be seen in Fig. 3, we have:

$$
\left[\begin{array}{l}
i_{s a} \\
i_{s b} \\
i_{s c}
\end{array}\right]=-\left[\begin{array}{l}
i_{f a} \\
i_{f b} \\
i_{f c}
\end{array}\right]
$$

Fig. 4 shows the DC/AC inverter control in grid-tied operation. The required power to be injected to the $\mathrm{AC}$ grid is set by the $P_{r e f}$ and $Q_{r e f}$ reference signals. These signals can be chosen by customers or remote power management units. This control strategy is called the $P-Q$ control scheme for gridtied mode. In this paper, the $P-Q$ control strategy has been designed based on the instantaneous power control strategy. The $\alpha-\beta$ transformation in Fig. 4 performs the following equations:

$$
\begin{aligned}
& {\left[\begin{array}{l}
v_{s \alpha} \\
v_{s \beta}
\end{array}\right]=T_{\alpha \beta}\left[\begin{array}{l}
v_{s a} \\
v_{s b} \\
v_{s c}
\end{array}\right]} \\
& T_{\alpha \beta}=\sqrt{\frac{2}{3}}\left[\begin{array}{ccc}
-1 & -\frac{1}{2} & -\frac{1}{2} \\
0 & \frac{\sqrt{3}}{2} & -\frac{\sqrt{3}}{2}
\end{array}\right]
\end{aligned}
$$

The $\alpha-\beta$ component related to the reference current of the DC/AC inverter can be expressed by equation (18).

$$
\left[\begin{array}{l}
i_{s \alpha}^{r e f} \\
i_{s \beta}^{r e f}
\end{array}\right]=\frac{1}{v_{s \alpha}^{2}+v_{s \beta}^{2}}\left[\begin{array}{cc}
v_{s \alpha} & -v_{s \beta} \\
v_{s \beta} & v_{s \alpha}
\end{array}\right]\left[\begin{array}{c}
P_{r e f} \\
Q_{r e f}
\end{array}\right]
$$

The $\alpha-\beta$ inverse transformation box, shown in Fig. 4 , calculates the three-phase current references to be fed into the HCC scheme. Thus:

$$
\begin{aligned}
& {\left[\begin{array}{l}
i_{s a}^{r e f} \\
i_{s b}^{r e f} \\
i_{s c}^{r e f}
\end{array}\right]=T_{a b c}\left[\begin{array}{l}
i_{s \alpha}^{r e f} \\
i_{s \beta}^{r e f}
\end{array}\right]} \\
& T_{a b c}=\sqrt{\frac{2}{3}}\left[\begin{array}{cc}
1 & 0 \\
-\frac{1}{2} & \frac{\sqrt{3}}{2} \\
-\frac{1}{2} & -\frac{\sqrt{3}}{2}
\end{array}\right]
\end{aligned}
$$

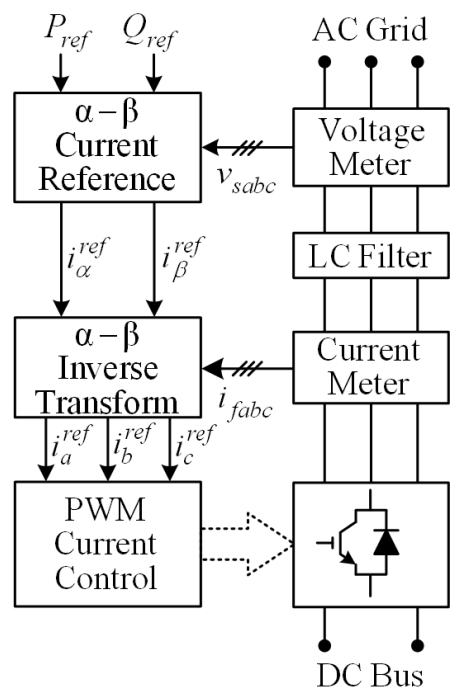

Fig. 4. Block diagram of the DC/AC inverter controller in grid-tied operation.

$$
\left[\begin{array}{l}
i_{f a}^{r e f} \\
i_{f b}^{r e f} \\
i_{f c}^{r e f}
\end{array}\right]=-\left[\begin{array}{l}
i_{s a}^{r e f} \\
i_{s b}^{r e f} \\
i_{s c f}^{r e f}
\end{array}\right]
$$

A comparison of the calculated reference currents and the actual currents generated by the DC/AC inverter will result in an error signal, which controls the switches of the inverter.

\section{B. Control strategy for stand-alone operation}

An average large signal model of a DC/AC inverter in the stand-alone operating condition is shown in Fig. 5. This inverter is represented with three voltage sources, $v_{f a}^{r e f}$, $v_{f b}^{r e f}$ and $v_{f c}^{r e f}$. The equations describing the DC/AC inverter voltages and currents are expressed by the following equation:

$$
\begin{aligned}
& {\left[\begin{array}{l}
v_{f a} \\
v_{f b} \\
v_{f c}
\end{array}\right]=\left[\begin{array}{l}
v_{l a} \\
v_{l b} \\
v_{l c}
\end{array}\right]+\left[\begin{array}{ccc}
R_{f} & 0 & 0 \\
0 & R_{f} & 0 \\
0 & 0 & R_{f}
\end{array}\right]\left[\begin{array}{l}
i_{f a} \\
i_{f b} \\
i_{f c}
\end{array}\right]} \\
& +\left[\begin{array}{ccc}
L_{f} & 0 & 0 \\
0 & L_{f} & 0 \\
0 & 0 & L_{f}
\end{array}\right] \frac{d}{d t}\left[\begin{array}{l}
i_{f a} \\
i_{f b} \\
i_{f c}
\end{array}\right]
\end{aligned}
$$

where, $v_{f a}, v_{f b}$ and $v_{f c}$ are the line to neutral three phase output voltages of the DC/AC inverter. $i_{f a}, i_{f b}$ and $i_{f c}$ are the three phase output currents. $v_{l a}, v_{l b}$ and $v_{l c}$ are the line to neutral three phase voltages of the AC loads. The voltage equations in the $d-q-0$ reference frame are as follows:

$$
\begin{aligned}
& {\left[\begin{array}{l}
v_{f d} \\
v_{f q} \\
v_{f 0}
\end{array}\right]=\left[\begin{array}{l}
v_{l d} \\
v_{l q} \\
v_{l 0}
\end{array}\right]+\left[\begin{array}{ccc}
R_{f} & 0 & 0 \\
0 & R_{f} & 0 \\
0 & 0 & R_{f}
\end{array}\right]\left[\begin{array}{l}
i_{f d} \\
i_{f q} \\
i_{f 0}
\end{array}\right]} \\
& +\left[\begin{array}{ccc}
L_{f} & 0 & 0 \\
0 & L_{f} & 0 \\
0 & 0 & L_{f}
\end{array}\right] \frac{d}{d t}\left[\begin{array}{l}
i_{f d} \\
i_{f q} \\
i_{f 0}
\end{array}\right]
\end{aligned}
$$




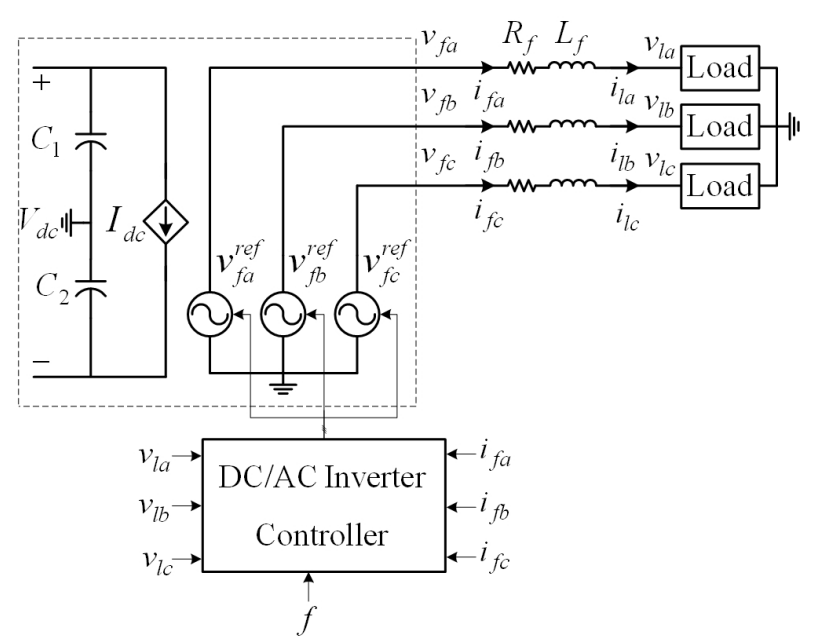

Fig. 5. Average large signal model of the DC/AC inverter in stand-alone mode.

$$
+\left[\begin{array}{ccc}
0 & -\omega L_{f} & 0 \\
-\omega L_{f} & 0 & 0 \\
0 & 0 & 0
\end{array}\right]\left[\begin{array}{c}
i_{f d} \\
i_{f q} \\
i_{f 0}
\end{array}\right]
$$

The circuit configuration and control scheme for a DC/AC inverter for the stand-alone operating condition is depicted in Fig. 6. The DC/AC inverter between the DC bus and the unbalanced AC load can be controlled by the $V-f$ control strategy, which regulates the voltage and the frequency of the unbalanced AC load. In the $V-f$ controller, it is clear that [12]:

- Frequency $(\omega)$ can be obtained by a phase lock loop (PLL) using a desirable frequency (e.g., $50 \mathrm{~Hz}$ ).

- The load phase voltages $\left(v_{l a}, v_{l b}\right.$ and $\left.v_{l c}\right)$ can be detected and transformed to the $d-q-0$ synchronously rotating reference frame using following equations:

$$
\begin{aligned}
& {\left[\begin{array}{l}
v_{l d} \\
v_{l q} \\
v_{l 0}
\end{array}\right]=T_{d q 0}\left[\begin{array}{l}
v_{l a} \\
v_{l b} \\
v_{l c}
\end{array}\right]} \\
& T_{d q 0}= \\
& \frac{2}{3}\left[\begin{array}{ccc}
\cos (\omega t) & \cos \left(\omega t-120^{\circ}\right) & \cos \left(\omega t+120^{\circ}\right) \\
-\sin (\omega t) & -\sin \left(\omega t-120^{\circ}\right) & -\sin \left(\omega t+120^{\circ}\right) \\
\frac{1}{2} & \frac{1}{2} & \frac{1}{2}
\end{array}\right]
\end{aligned}
$$

The load phase voltage should be kept balanced and sinusoidal with a constant amplitude and frequency. Therefore, the expected load voltage in the $d-q-0$ reference frame should only have the following value:

$$
\left[\begin{array}{c}
v_{l d}^{e x p} \\
v_{l q}^{e x p} \\
v_{l 0}^{e x p}
\end{array}\right]=\left[\begin{array}{c}
0 \\
0.4 \sqrt{\frac{2}{3}} \\
0
\end{array}\right]
$$

The DC/AC inverter controller based on the $d-q-0$ rotating reference frame consists of an inner current loop and an outer voltage loop in a three channel arrangement. The current and voltage loops include independent PI controllers for the $d, q$ and 0 channels to eliminate steady state errors. The reference load current loops in the $d-q-0$ coordinate are:

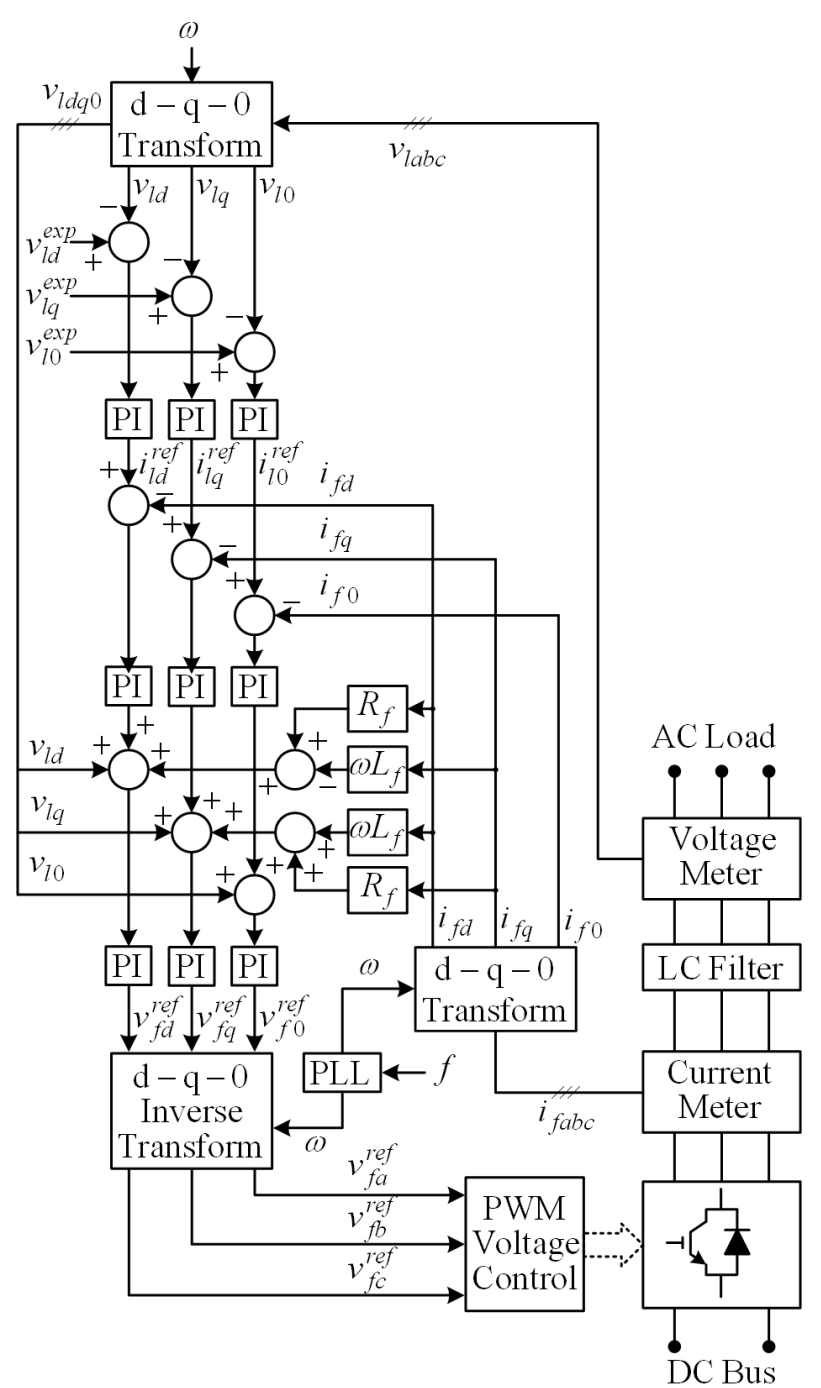

Fig. 6. Block diagram of the DC/AC inverter controller in stand-alone operation.

$$
\left[\begin{array}{l}
i_{l d}^{r e f} \\
i_{l q}^{r e f} \\
i_{l 0}^{r e f}
\end{array}\right]=\left[\begin{array}{l}
P I\left(v_{l d}-v_{l d}^{e x p}\right) \\
P I\left(v_{l q}-v_{l q}^{e x p}\right) \\
P I\left(v_{l 0}-v_{l 0}^{e x p}\right)
\end{array}\right]
$$

The output signals from the PI controller can be expressed by equation (26).

$$
\begin{aligned}
& {\left[\begin{array}{c}
v_{f d}^{r e f} \\
v_{f q}^{r e f} \\
v_{f 0}^{r e f}
\end{array}\right]=\left[\begin{array}{c}
v_{l d} \\
v_{l q} \\
v_{l 0}
\end{array}\right]+\left[\begin{array}{c}
P I\left(i_{l d}^{r e f}-i_{f d}\right) \\
P I\left(i_{l q}^{r e f}-i_{f q}\right) \\
P I\left(i_{l 0}^{r e f}-i_{f 0}\right)
\end{array}\right]} \\
& +\left[\begin{array}{c}
-\omega L_{f} i_{f q} \\
-\omega L_{f} i_{f d} \\
0
\end{array}\right]+\left[\begin{array}{c}
R_{f} i_{f d} \\
R_{f} i_{f q} \\
0
\end{array}\right]
\end{aligned}
$$

The reference output voltages for the DC/AC inverter are transformed to the $a-b-c$ by using an inverse synchronously rotating frame. 


$$
\begin{aligned}
& {\left[\begin{array}{c}
v_{f a}^{r e f} \\
v_{f b}^{r e f} \\
v_{f c}^{r e f}
\end{array}\right]=T_{a b c}\left[\begin{array}{c}
v_{f d}^{r e f} \\
v_{f q}^{r e f} \\
v_{f 0}^{r e f}
\end{array}\right]} \\
& T_{a b c}\left[\begin{array}{ccc}
\cos (\omega t) & -\sin (\omega t) & 1 \\
\cos \left(\omega t-120^{\circ}\right) & -\sin \left(\omega t-120^{\circ}\right) & 1 \\
\cos \left(\omega t+120^{\circ}\right) & -\sin \left(\omega t+120^{\circ}\right) & 1
\end{array}\right]
\end{aligned}
$$

Then the available voltages in the $a-b-c$ coordinates are compared with the triangular wave provided by PWM voltage control block. Therefore the output provides the switching pattern of a DC/AC inverter.

\section{Simulation Results}

The ICS for cascaded DG modules that is shown in Fig. 1 has been modeled and simulated based on PSCAD/EMTDC in order to verify the performance of the proposed control systems, both in grid-tied and stand-alone applications. The simulation scenarios are focused on grid-tied and stand-alone suitable operations supplying unbalanced passive loads. All time functions are in seconds. The rated power of each DG module is $10 \mathrm{~kW}$. Thus, the system is an aggregate DG of $50 \mathrm{~kW}$. For each boost converter, the DC voltage set point is $150 \mathrm{~V}$, the droop coefficient is designed to obtain a $\% 5$ droop at its rated power operation. The capacitor at the DC link side and the inductor at the DG module side have been designed using equations (14) and (15). The output voltage of each DG module is $75 \mathrm{~V}$. The droop coefficient of each boost converter is 0.11875 .

\section{A. Grid-tied operation}

In this case, the $P-Q$ control scheme is applied. The reference values of $P_{\text {ref }}$ and $Q_{\text {ref }}$ have been changed from $20 \mathrm{~kW}$ to $40 \mathrm{~kW}$ and from $5 \mathrm{kVAr}$ to $10 \mathrm{kVAr}$ at $\mathrm{t}=2 \mathrm{~s}$, and then from $40 \mathrm{~kW}$ to $20 \mathrm{~kW}$ and from $10 \mathrm{kVAr}$ to 5 kVAr at $\mathrm{t}=3 \mathrm{~s}$, respectively. Fig. 7 shows $P$ and $Q$ delivered to the grid. In Fig. 7, the output power of the system is varied following the trace of the reference points. However, the proposed system delivers the active and reactive powers to the grid, which matches the reference values of $P$ and $Q$. Fig. 8 shows the output voltage and power of each DG module. In Fig. 8(a), when the power reference variations are applied, the DC terminal voltage of each boost converter is decreased. In Fig. 8(b), the instantaneous active powers of the DG modules are equal. These results indicate the effectiveness of the control system, shown in Fig. 2, for boost converters, in providing proper DC bus voltage regulation and proper load sharing of aggregated DG modules. Fig. 9(a) shows the power output from the DC bus, which matches the above grid connected condition. The DC bus voltage of the each boost converter is shown in Fig 9(b).

Note that the DC output voltage of each boost converter is decreased as the reference values of the inverter are increased, and vice versa, but it remains within its specified limits. In the steady state condition, as shown in Fig. 8 and 9, we have $V_{d c}$ $=147.03 \mathrm{kV}$ and $P_{d g}=4.058 \mathrm{~kW}$. These results can be verified by equation (7).
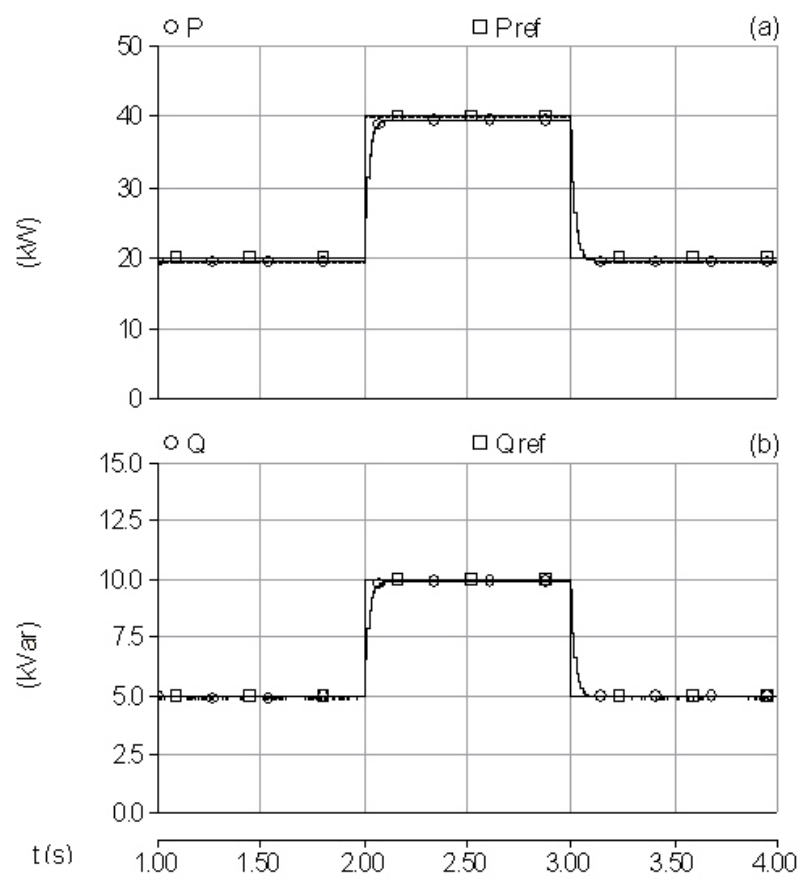

Fig. 7. $P$ and $Q$ delivered to the grid.
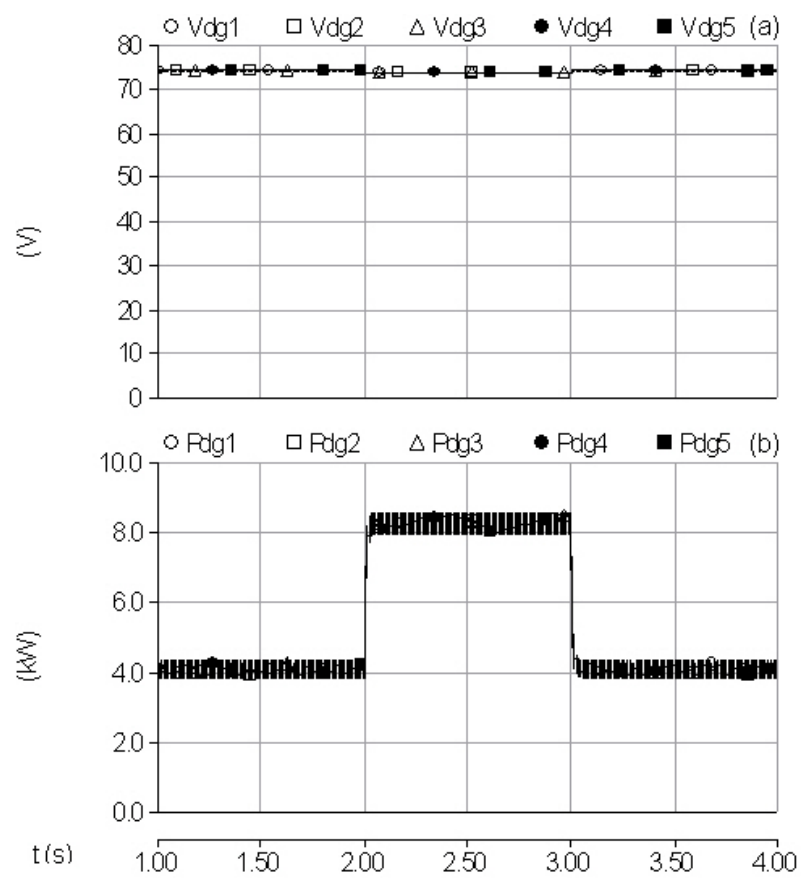

Fig. 8. DC terminal voltages and active powers of DG modules.

Fig. 10 shows the grid-side phase voltages and the line currents of the inverter. The line currents change with power reference variations. However, the inverter can deliver the generator's power to the grid with a low harmonic current. This verifies the effectiveness of the $P-Q$ control strategy.

\section{B. Stand-alone operation}

The response of proposed interconnection system to unbalanced loading conditions in the stand-alone mode has been studied, too. However, the $V-f$ control scheme is activated. Unbalanced load No. 1 has been changed to unbalanced load 

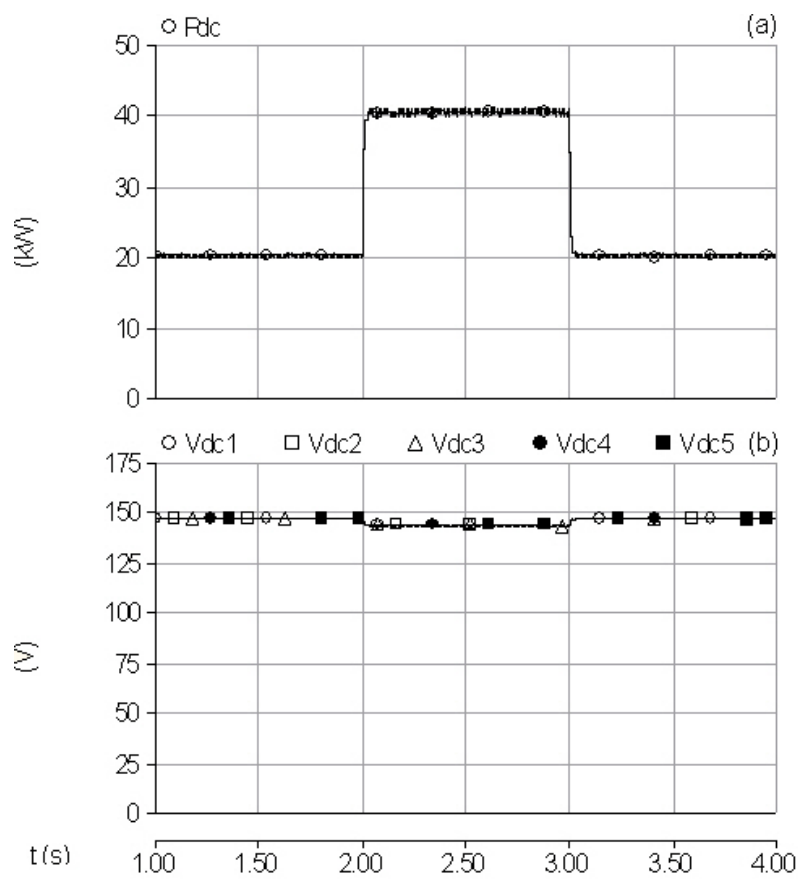

Fig. 9. (a) Power output from the DC bus and (b) DC bus voltages of boost converters.
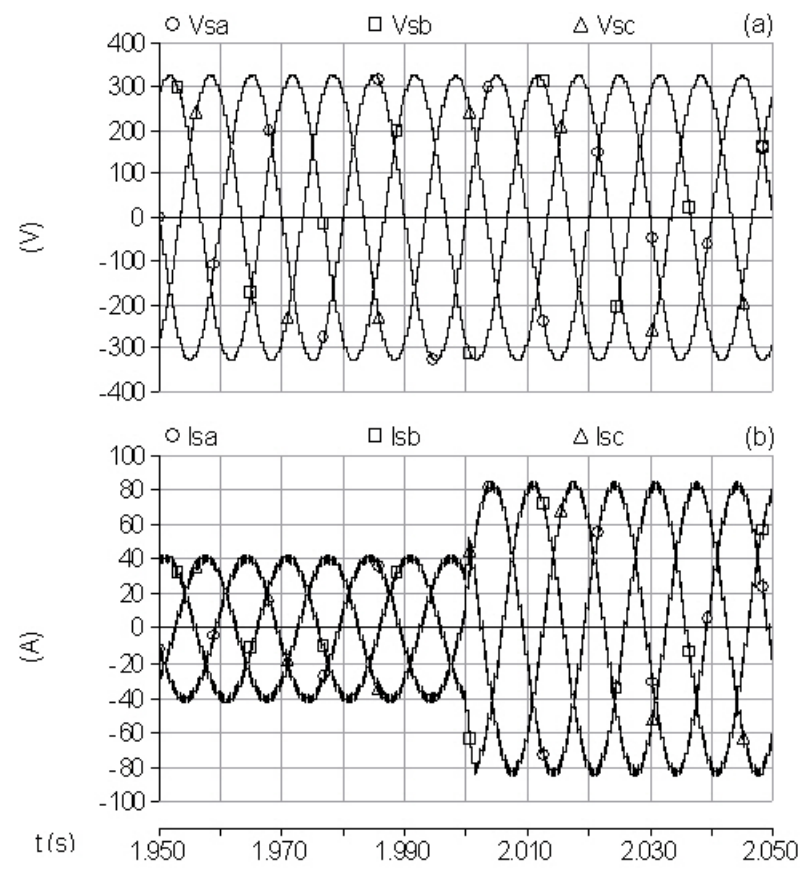

Fig. 10. Grid-side phase voltages and line currents of the inverter.

No. 2 at $\mathrm{t}=2 \mathrm{~s}$ and at $\mathrm{t}=3 \mathrm{~s}$ the load has again been changed to its initial value, i.e., unbalanced load No. 1. The parameters of load No. 1 and 2 are given in appendix A. Fig. 11 shows the active and reactive power consumed by the unbalanced AC loads. Fig. 12 shows the output voltage and power for each of the DG modules under the above unbalanced loads in the islanding condition. In Fig. 12(a), the DC terminal voltage of each boost converter is decreased. In Fig. 12(b), the instantaneous active powers of the DG modules are equal. These results indicate the effectiveness of the control system,
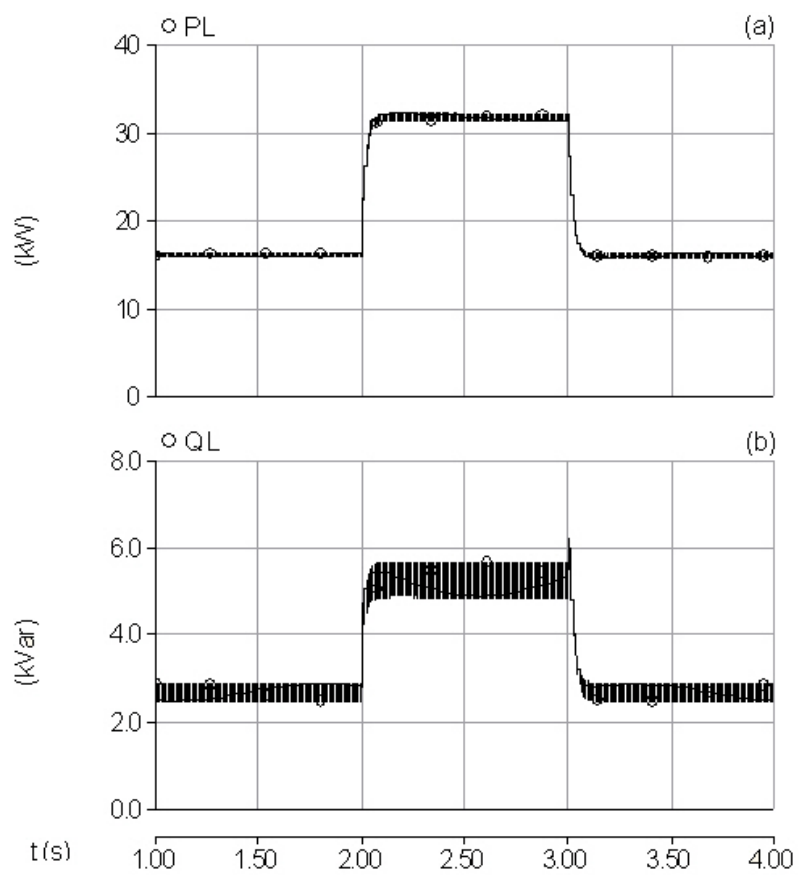

Fig. 11. $P$ and $Q$ consumed with unbalanced loads.
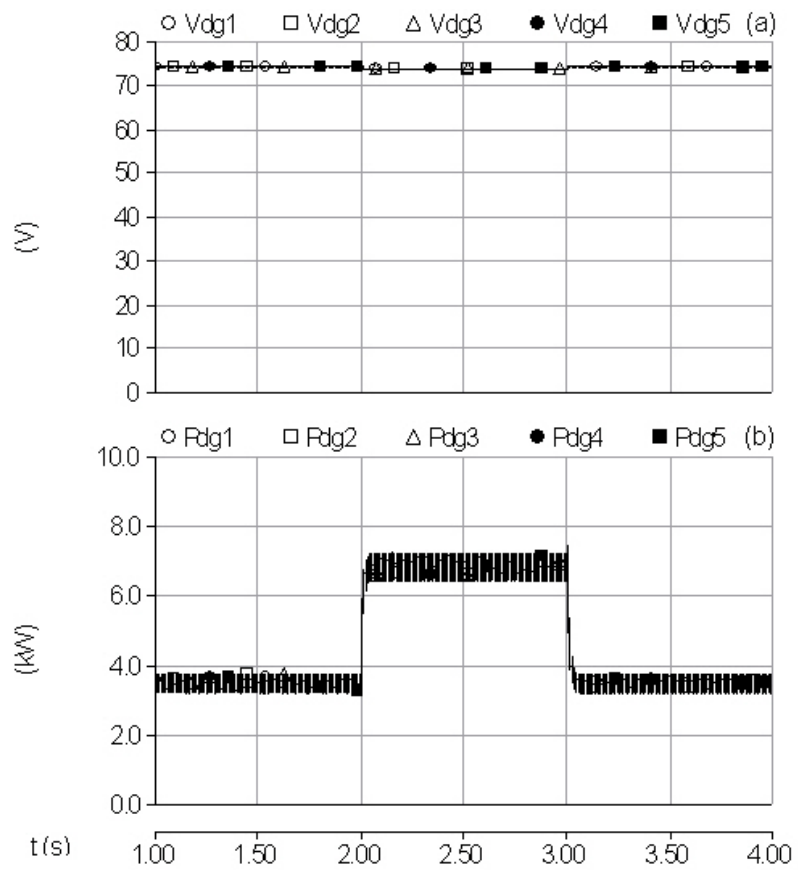

Fig. 12. DC terminal voltages and active powers of DG modules.

shown in Fig. 2, for boost converters, providing proper DC bus voltage regulation and proper load sharing of aggregated DG modules.

Fig. 13(a) shows the power output from the DC bus, which matches the above unbalanced load variations. The DC bus voltage of each boost converter is shown in Fig 13(b). Note that the DC output voltage of each boost converter decreases as the unbalanced load variations are applied, and vice versa, but it remains within its specified limits. In the steady state condition, as shown in Fig. 12 and 13, we have $V_{d c}=147.55$ $\mathrm{kV}$ and $P_{d g}=3.38 \mathrm{~kW}$. These results can be verified by 

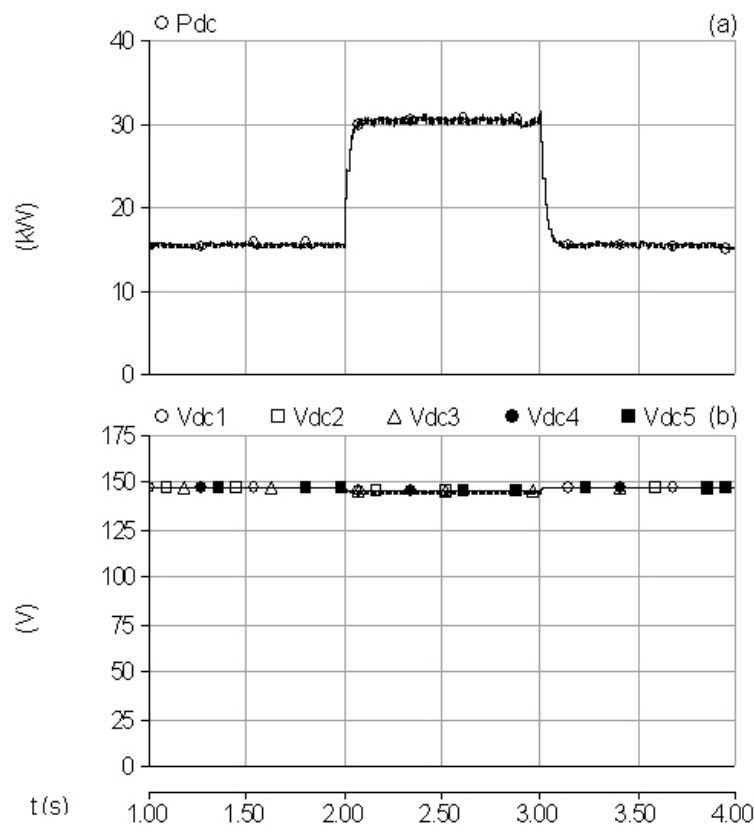

Fig. 13. (a) Power output from the DC bus and (b) DC bus voltages of boost converters.
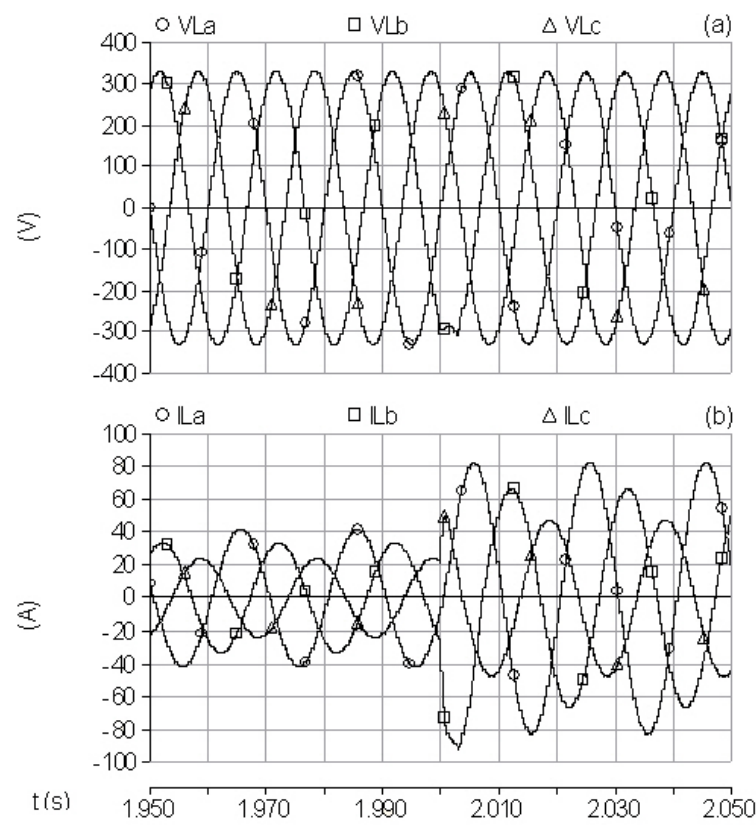

Fig. 14. Phase voltages and Line currents at unbalanced load terminals.

equation (7). Fig. 14 shows the phase voltages and line currents at the unbalanced load terminals. The inverter maintains the output at the desired level irrespective of the load applied to the system.

The AC voltage level across the load remains unchanged with the load variation switching and it stays at the reference value $V_{l q}^{e x p}$ throughout the simulation. However, the balanced voltages are provided for the unbalanced AC loads while the load phase currents are not sinusoidal. This is because of the ability of the inverter to control its output voltage. The 3-phase line currents at the load terminals change with the load variation switching. To quantify the level of the voltage unbalance, the percentage of unbalance is expressed in accordance with the definition of the "degree of unbalance in three phase system" [13]. In this case, the negative sequence unbalance is lower then $1 \%$ which is acceptable. It must be noticed that international standards admit unbalances lower than 2\% [13]. This verifies the effectiveness of the $V-f$ control strategy for stand-alone operation.

\section{CONCLUSIONS}

The modeling of an ICS, based on a cascaded architecture using the proposed control systems, suitable for use in both stand-alone and grid-tied applications is presented in this paper. In this paper, the control system for converters in an ICS based cascaded architecture has been studied. For DC voltage control in each boost converter, the droop controller method is used. This method provides stable operation and proper load sharing of the DG modules without requiring fast communication systems. Evaluations of grid-tied and standalone operation modes show that it is suitable for dynamic studies. Also a different operation mode control strategy for DC/AC inverters has been simulated. The controller designs for the different operating conditions of a DC/AC inverter are given using the average large signal model. A $P-Q$ control scheme based instantaneous power control strategy is used on the inverter to control the active and reactive power delivered from the aggregated DG modules to the utility grid. A novel $V-f$ control scheme based $d-q-0$ transformed currentvoltage controller is used on the inverter under unbalanced load conditions.

\section{APPENDIX A}

The parameters of the unbalanced AC loads used for the simulations are as follows:

RL load No. 1:

$Z_{l a 1}=7.8586 \angle 11.5279^{\circ} \Omega, Z_{l b 1}=9.8264 \angle 9.196^{\circ} \Omega$ and $Z_{l c 1}=13.7898 \angle 6.5432^{\circ} \Omega$

RL load No. 2:

$Z_{l b 2}=3.9293 \angle 11.5279^{\circ} \Omega, Z_{l b 2}=4.9132 \angle 9.196^{\circ} \Omega$ and $Z_{l c 2}=6.8949 \angle 6.5432^{\circ} \Omega$

\section{REFERENCES}

[1] IEEE Std 1547.1, IEEE Standard Conformance Test Procedures for Equipment Interconnecting Distributed Resources with Electric Power Systems, 2005.

[2] N. Moadabi, M. Mahmoodi, and G. B. Gharehpetian, "Control Systems of Distributed Generation Modules Aggregated by Cascaded Boost Converters," Proc. of the International Conference on Renewable Energies and Power Quality, ICREPQ'07, Mar. 2007.

[3] Agustoni A., Brenna M., Tironi E., "Proposal for a High Quality DC Network with Distributed Generation," CIRED, 17-th International Conference on Electricity Distribution, 12-15 May 2003.

[4] Mahmoodi M., Gharehpetian G. B., Abedi M., Noroozian R., "Novel and Simple Control Strategy for Fuel Cell Converters in DC Distribution Systems," First International Power and Energy Conference, PECon 2006, pp. 358-362, Nov. 2006.

[5] Mahmoodi M., Gharehpetian G. B., Abedi M., Noroozian R., "A Suitable Control Strategy for Source Converters and a Novel Load- Generation Voltage Control Scheme for DC Voltage Determination in DC Distribution Systems," First International Power and Energy Conference PECon 2006, pp. 363-367, Nov. 2006.

[6] CIGRE Technical Brochure on Modeling New Forms of Generation and Storage, Nov. 2000. 
[7] S. Guda, C. Wang and M. Nehrir, "Modeling of Microturbine Power Generation Systems," Electric Power Components and Systems, Vol. 34, No.9, pp. 1027-1041, 2006.

[8] F. S. Pai, "An Improved Utility Interface for Microturbine Generation System with Stand-Alone Operation Capabilities," IEEE Trans. on industrial electronics, Vol. 53, No. 5, pp. 1529-1537, 2006.

[9] D. N. Gaonkar and R. N. Patel, "Modeling and simulation of microturbine based distributed generation system," Proc. of the IEEE Conf. on Power System, pp. 1-5, Apr. 2006.

[10] C. Wang, M. H. Nehrir and H. Gao, "Control of PEM Fuel Cell Distributed Generation Systems," IEEE Trans. Energy Conversion, Vol. 21, No. 2, pp. 586-595, 2006.

[11] P. Karlsson and J. Svensson, "DC Bus Voltage Control for a Distributed Power System," IEEE Trans. on Power Electronics, Vol. 18, No. 6, pp. 1405-1412, Nov. 2003.

[12] R. Noroozian, M. Abedi, G.B. Gharehpetian, S.H. Hosseini, "Combined operation of DC isolated distribution and PV systems for supplying unbalanced AC loads," Renewable Energy 34 (2009) 899-908.

[13] T. Short, Electric Power Distribution Handbook, CRC Press, 2004.

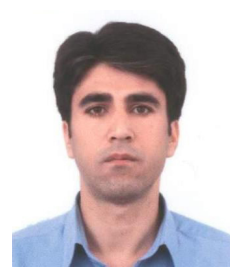

Reza Noroozian was born in Bonab, Iran, in 1975 He received a B.Sc. degree from Tabriz University, Tabriz, Iran, in 2000, and his M.Sc. and Ph.D. from the Amirkabir University of Technology (AUT), Tehran, Iran, in 2003 and 2008, respectively, all Electrical Engineering. Currently, he is an Assistant Professor in the Department of Electrical Engineering, Faculty of Engineering, Zanjan University, Zanjan, Iran. His research interests include power system, distributed generation, power electronic and power quality.

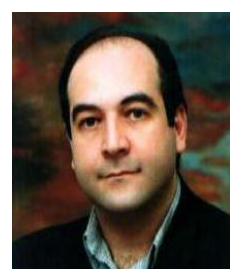

Gevorg Gharehpetian was born in Tehran, in 1962. $\mathrm{He}$ received his B.S. and M.S. degrees in Electrical Engineering in 1987 and 1989 from Tabriz University, Tabriz, Iran and Amirkabir University of Technology (AUT), Tehran, Iran, respectively. In 1989 he joined the Electrical Engineering Department of AUT as a Lecturer. He received a Ph.D. in Electrical Engineering from Tehran University, Tehran, Iran, in 1996. As a $\mathrm{Ph} . \mathrm{D}$. student he received a scholarship from DAAD
(German Academic Exchange Service) from 1993 to 1996 and he was with the High Voltage Institute of RWTH Aachen, Aachen, Germany. He held the position of Assistant Professor in AUT from 1997 to 2003, and he has been an Associate Professor since 2004. Dr. Gharehpetian is a Senior Member of the Iranian Association of Electrical and Electronics Engineers (IAEEE), a member of the IEEE and a member of the central board of the IAEEE. Since 2004 he has been the Editor-in-Chief of the Journal of IAEEE. The Power Engineering Group of AUT has been selected as a Center of Excellency on Power Systems in Iran since 2001. He has been a member of this center and since 2004 and is currently the Research Deputy. Since November 2005, he has been the Director of the Industrial Relation Office of AUT. He is the author of more than 222 journal and conference papers. His teaching and research interest include power system and transformer's transients, FACTS devices and HVDC transmission.

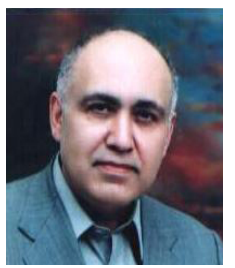

Mehrdad Abedi received his B.S., M.S. and Ph.D. from Tehran University, London University and Newcastle University in 1970, 1973, and 1977, respectively. He worked for G.E.C. (U.K) until 1978. He then joined the Electrical Engineering Dept of Amirkabir University (Tehran, Iran) where he is now a Professor and a member of the Center of Excellency on Power System. Prof. Abedi has published more than 25 books and 160 papers in various journals and conferences. He is a distinguished Professor in Iran and is a prizewinner for two of his outstanding books. He is also a member of Iranian Academy of Science and member of CIGRE. His main interests are electrical machines and power systems modeling, operation and control.

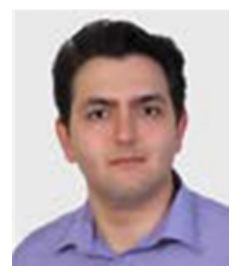

Mishel Mahmoodi was born in Tehran, Iran, in 1982. He received his B.S. in Electrical Power Engineering in 2004 from the Amirkabir University of Technology (AUT), Tehran, Iran. As a B.S. student, he recieved technical experience in TU M?nchen, Germany in the summer of 2004, which was supported by the International Association for the Exchange of Students for Technical Experience (IAESTE). He received his M.S. in Electrical Power Engineering in 2006 from the Amirkabir University of Technology (AUT), Tehran, Iran. His research interests include distributed generation systems, distribution power systems and power electronics control. 